\title{
Relation of Body Weight Change to Changes in Atherogenic Traits; A Study of Middle-Aged Japanese Obese Male Office Workers
}

\author{
Noriyuki NAKANISHI ${ }^{1}$ *, Koji NAKAMURA ${ }^{2}$, Kenji SUZUKI ${ }^{3}$, \\ Yoshio MATSUO ${ }^{1}$ and Kozo TATARA ${ }^{1}$

\footnotetext{
${ }^{1}$ Department of Social and Environmental Medicine, Course of Social Medicine, Osaka University Graduate School of Medicine F2, 2-2 Yamada-oka, Suita-shi, Osaka 565-0871, Japan

${ }^{2}$ Medical Office, Osaka Main Office, Takenaka Corporation, 4-1-13 Honmachi, Chuo-ku, Osaka 541-0053, Japan

${ }^{3}$ Japan Labor and Welfare Association, 1-24-4 Ebisu, Shibuya-ku, Tokyo 150-0013, Japan
}

Received August 23, 1999 and accepted December 8, 1999

\begin{abstract}
We examined the effect of body weight change on the modification of atherogenic risk factors in $\mathbf{2 9 6}$ middle-aged obese male office workers without medication for hypertension, dyslipidemia, hyperuricemia or diabetes mellitus. During a 1-year education program, $39.2 \%$ of the participants could reduce their weight, and the percentage of those who lost $2 \mathrm{~kg}$ or more was only $\mathbf{1 7 . 7 \%}$. Concomitant with the decrease of weight, however, the levels of systolic and diastolic blood pressures, total cholesterol, triglyceride, uric acid and hemoglobin $A_{1 c}$ and the ratio of total cholesterol to high-density lipoprotein (HDL) cholesterol decreased significantly, whereas the HDL cholesterol level increased significantly. In a multivariate regression analysis, in addition to the initial risk-factor level, weight change was an important factor determining the changes in atherogenic risk factors. Changes in alcohol consumption were significantly associated with the changes in systolic blood pressure and HDL cholesterol levels. Changes in cigarettes smoking also showed significant associations with the changes in triglyceride level and the ratio of total cholesterol to HDL cholesterol. These results suggest that although the education program for controlling weight may have limited success, weight reduction exhibits beneficial changes in the atherogenic risk-factor profile in middle-aged obese men.
\end{abstract}

Key words: Japanese men, Middle age, Office workers, Education, Overweight, Weight reduction, Atherogenic risk factors

\section{Introduction}

Excess body weight is widely recognized to be an important health problem in industrialized societies ${ }^{1-11)}$. Hazards of obesity include elevated total and low-density lipoprotein (LDL) cholesterol levels, decreased high-density lipoprotein (HDL) cholesterol levels, hypertension, and increased prevalence and incidence of cardiovascular disease, gout, diabetes mellitus, and other diseases.
The appropriate approach to reduce the obesity-related health risk is to reduce body weight. Many studies have shown that weight reduction leads to an improvement of the atherogenic risk-factor profile ${ }^{11-16)}$. However, there are few trials at workplace to test the feasibility and effectiveness of health education in controlling overweight. The present paper describes whether a 1-year workplace-based education program controls body weight levels and reduces the levels of atherogenic risk factors in middle-aged Japanese obese male office workers.

*To whom correspondence should be addressed. 


\section{Materials and Methods}

To evaluate the effect of body weight change on the modification of atherogenic risk factors, a 1-year education program was conducted on overweight employees of $\mathrm{T}$ Corporation, which is one of the biggest building contractors in Osaka, Japan, between May 1997 and May 1998. The surveillance population consisted of 1,937 Japanese male office workers aged 30 to 59 years in May 1997. At the initial examination, weight and height were measured with the subjects in typical indoor clothing but without shoes. Body mass index (BMI) was calculated as weight $/$ height ${ }^{2}\left(\mathrm{~kg} / \mathrm{m}^{2}\right)$, and BMI of $\geq 25.5 \mathrm{~kg} / \mathrm{m}^{2}$ was defined as overweight. This cut-off point corresponds approximately to $120 \%$ of medians of body weight distributions by height for healthy Japanese men aged 20 years and older ${ }^{17}$. Alcohol intake was obtained by interview as usual weekly intake of alcohol in $g o$ (a traditional Japanese unit of volume corresponding to $23 \mathrm{~g}$ ethanol) and converted to grams of ethanol per day. One $g o$ is $180 \mathrm{ml}$ of sake and corresponds to one bottle of beer (633 $\mathrm{ml})$, two shots $(70 \mathrm{ml})$ of whisky, or two glasses $(180 \mathrm{ml})$ of wine. An interview was also conducted to ascertain the number of current cigarettes smoked per day. Blood pressure was measured to the nearest $2 \mathrm{mmHg}$ with a standard sphygmomanometer on the right arm of subjects sitting after 5 min rest during the day (between $9 \mathrm{AM}$ and $3 \mathrm{PM}$ ), and Korotkoff phases I and V were taken as representing systolic and diastolic blood pressure, respectively. Following the blood pressure measurement, fasting blood samples were drawn from an antecubital vein. Total cholesterol, triglyceride, HDL cholesterol, and uric acid were analyzed with an Olympus AU-5200 (Olympus Japan Co., Ltd., Tokyo, Japan) by the Nihon Clinical Laboratories Inc. (Tokyo, Japan). Hemoglobin $\mathrm{A}_{1 \mathrm{c}}\left(\mathrm{HbA}_{1 \mathrm{c}}\right)$ was determined with a JOOKOO's automated glycohemoglobin analyzer system HS-8 (Jookoo Co., Ltd., Tokyo, Japan). A medical and prescription drug-use history was also completed by examining physicians. Of a total of 1,937 subjects, $413(21.3 \%)$ were regarded as overweight. Fifty eight subjects $(14.0 \%)$ were under medication for hypertension, dyslipidemia, hyperuricemia or diabetes mellitus. A total of 355 overweight subjects, who had no medication for hypertension, dyslipidemia, hyperuricemia or diabetes mellitus, were invited to the program between July 1997 and August 1997. Among 355 overweight subjects, the proportions of those with abnormal findings in medical test items were $27.0 \%$ for systolic blood pressure $\geq 140 \mathrm{mmHg}, 27.0 \%$ for diastolic blood pressure $\geq 90 \mathrm{mmHg}, 27.6 \%$ for total cholesterol $\geq 220 \mathrm{mg} / \mathrm{dl}, 15.2 \%$ for HDL cholesterol $<40 \mathrm{mmHg}, 20.0 \%$ for the ratio of total cholesterol to HDL cholesterol $\geq 5.0,33.0 \%$ for triglyceride $\geq 160 \mathrm{mg} / \mathrm{dl}, 11.0 \%$ for uric acid $\geq 8.0 \mathrm{mg} / \mathrm{dl}$ and $5.9 \%$ for $\mathrm{HbA}_{1 \mathrm{c}} \geq 6.0 \%$. Furthermore, the percentages of those who drank alcohol every day and smoked cigarettes currently were $74.9 \%$ and $43.7 \%$, respectively. Classes were composed of health education by physicians on how to control body weight for prevention of coronary heart disease (CHD) and practical sessions directed by practice nurses on how to reduce alcohol intake; stop or refrain from cigarette smoking; consider a nutritional balance; and increase physical activity, especially a brisk walk 30 minutes or more a day. One more health education was held in November 1997 and the participants were encouraged to promote practices such as appropriate alcohol consumption, avoiding smoking, considering a nutritional balance, and regularity of physical exercise. Of a total of 355 overweight subjects, 309 (87.0\%) participated in the program. Thirteen subjects $(4.2 \%)$ began to be administered drugs for hypertension, dyslipidemia, hyperuricemia or diabetes mellitus during the observation period, and the remaining 296 constituted the study population. The measurement of BMI and blood pressure was reexamined in May 1998. Total cholesterol, triglyceride, HDL cholesterol, uric acid, and $\mathrm{HbA}_{1 \mathrm{c}}$ were also determined with the same laboratory procedures. Quality control of the laboratory was maintained by internal method, and the inter- and intraassay coefficients of variation for each blood sample data were within 3\% from 1997 to 1998.

To study the influence of weight change on the changes in atherogenic risk factors, the subjects were divided into four subgroups, depending on their weight change during one year; weight loss of $\geq 2.0 \mathrm{~kg}$, weight loss of 0.1 to 1.9 $\mathrm{kg}$, weight gain of 0 to $1.9 \mathrm{~kg}$, and weight gain of $\geq 2.0 \mathrm{~kg}$. For statistical assessment, paired $t$ test was used to assess the 1-year changes in the clinical and laboratory data among individuals. One-way analysis of variance (ANOVA) was used to compare the means of the subgroups and the multiple range test by Scheffé's method was performed for comparing the significance of mean differences between subgroups when the ANOVA result was significant. Multiple regression analysis was performed to examine the effects of initial riskfactor level, age, initial body weight, change of body weight, initial alcohol intake, change of alcohol intake, initial cigarette smoking, and change of cigarette smoking on the change of the respective risk factor during one year. The distribution of blood pressure and blood laboratory data showed some skewing to the right but only appreciably so for serum triglyceride. The data were also analyzed with logarithmic transformation of the triglyceride, but the resulting differences were small and unimportant and are not presented.

Data analysis was performed with the SPSS/PC statistical 
package (Marija J. Norusis, SPSS Inc., Chicago, IL, USA). All reported p-values are two-tailed and a p-value of less than 0.05 was considered significant.

\section{Results}

Baseline characteristics of the study subjects according to body weight change during one year are shown in Table 1. The percentage of those who reduced their body weight was $39.2 \%$, and the proportion of those who lost $2 \mathrm{~kg}$ or more was only $17.7 \%$. As for baseline characteristics, there were no statistically significant differences in the clinical and laboratory data among the four subgroups according to weight change.

The mean values of the changes of selected variables according to body weight change during one year are shown in Table 2. As for the changes of selected variables among individuals, mean values of body weight or BMI did not change significantly. Some atherogenic risk factors such as the levels of total cholesterol, the ratio of total cholesterol to HDL cholesterol and $\mathrm{HbA}_{1 \mathrm{c}}$ showed small but significant increases. Among the four groups according to body weight

Table 1. Baseline characteristics of 296 obese male office workers aged 30 to 59 years according to body weight change during one year

\begin{tabular}{|c|c|c|c|c|c|}
\hline \multirow[b]{2}{*}{ Variable (Unit) } & \multicolumn{5}{|c|}{ Body weight change during one year } \\
\hline & $\begin{array}{c}\leq-2.0 \mathrm{~kg} \\
\mathrm{n}=52\end{array}$ & $\begin{array}{c}-1.9 \sim-0.1 \mathrm{~kg} \\
\mathrm{n}=65\end{array}$ & $\begin{array}{c}0 \sim 1.9 \mathrm{~kg} \\
\mathrm{n}=112\end{array}$ & $\begin{array}{c}\geq 2.0 \mathrm{~kg} \\
\mathrm{n}=67\end{array}$ & $\begin{array}{c}\text { Total } \\
\mathrm{n}=296\end{array}$ \\
\hline Age (years) & $44.5 \pm 7.7$ & $46.9 \pm 8.1$ & $45.5 \pm 8.4$ & $44.4 \pm 7.4$ & $45.4 \pm 8.0$ \\
\hline Weight (kg) & $79.6 \pm 7.7$ & $78.9 \pm 8.6$ & $78.6 \pm 7.6$ & $78.2 \pm 8.5$ & $78.8 \pm 8.0$ \\
\hline Body mass index $\left(\mathrm{kg} / \mathrm{m}^{2}\right)$ & $27.4 \pm 1.7$ & $27.6 \pm 2.7$ & $27.3 \pm 1.7$ & $27.2 \pm 1.6$ & $27.4 \pm 2.0$ \\
\hline Systolic blood pressure (mmHg) & $133.5 \pm 16.2$ & $128.0 \pm 13.0$ & $129.5 \pm 14.1$ & $132.3 \pm 16.8$ & $130.5 \pm 15.0$ \\
\hline Diastolic blood pressure $(\mathrm{mmHg})$ & $84.0 \pm 12.0$ & $80.2 \pm 10.8$ & $81.2 \pm 11.7$ & $82.7 \pm 12.4$ & $81.8 \pm 11.8$ \\
\hline Total cholesterol (mg/dl) & $204.5 \pm 36.9$ & $205.2 \pm 29.4$ & $198.5 \pm 31.0$ & $208.8 \pm 25.4$ & $203.3 \pm 30.7$ \\
\hline HDL cholesterol (mg/dl) & $48.0 \pm 9.8$ & $50.1 \pm 10.5$ & $50.5 \pm 11.7$ & $52.4 \pm 9.7$ & $50.4 \pm 10.7$ \\
\hline Total cholesterol/HDL cholesterol & $4.28 \pm 0.90$ & $4.21 \pm 1.06$ & $4.11 \pm 1.07$ & $4.11 \pm 0.91$ & $4.16 \pm 1.00$ \\
\hline Triglyceride $(\mathrm{mg} / \mathrm{dl})$ & $166.8 \pm 128.4$ & $157.6 \pm 99.5$ & $145.5 \pm 101.1$ & $131.7 \pm 67.4$ & $148.8 \pm 100.0$ \\
\hline Uric acid $(\mathrm{mg} / \mathrm{dl})$ & $6.5 \pm 1.2$ & $6.4 \pm 1.5$ & $6.1 \pm 1.4$ & $6.3 \pm 1.2$ & $6.3 \pm 1.4$ \\
\hline Hemoglobin $\mathrm{A}_{1 \mathrm{c}}(\%)$ & $5.3 \pm 0.8$ & $5.2 \pm 0.5$ & $5.2 \pm 0.7$ & $5.2 \pm 0.7$ & $5.2 \pm 0.7$ \\
\hline Alcohol intake (g/day of ethanol) & $23.3 \pm 17.6$ & $20.2 \pm 19.6$ & $23.3 \pm 20.4$ & $22.7 \pm 20.6$ & $22.5 \pm 19.7$ \\
\hline Smoking (cigarettes/day) & $14.7 \pm 17.0$ & $13.7 \pm 15.6$ & $11.7 \pm 16.1$ & $17.0 \pm 17.8$ & $13.9 \pm 16.6$ \\
\hline
\end{tabular}

Results are presented as means \pm standard deviations.

Table 2. Changes of selected variables according to body weight change during one year

\begin{tabular}{|c|c|c|c|c|c|c|c|}
\hline \multirow[b]{2}{*}{ Change of variable (Unit) } & \multicolumn{6}{|c|}{ Body weight change during one year } & \multirow[b]{2}{*}{$\begin{array}{l}\text { Analysis } \\
\text { of variance }\end{array}$} \\
\hline & $\begin{array}{c}\leq-2.0 \mathrm{~kg} \\
\mathrm{n}=52\end{array}$ & $\begin{array}{c}-1.9 \sim-0.1 \mathrm{~kg} \\
\mathrm{n}=65\end{array}$ & $\begin{array}{c}0 \sim 1.9 \mathrm{~kg} \\
\mathrm{n}=112\end{array}$ & $\begin{array}{c}\geq 2.0 \mathrm{~kg} \\
\mathrm{n}=67\end{array}$ & $\begin{array}{c}\text { Total } \\
\mathrm{n}=296\end{array}$ & & \\
\hline Weight (kg) & $-3.3 \pm 1.5 \quad a$ & $-0.9 \pm 0.4 \quad b$ & $0.8 \pm 0.6 \quad c$ & $3.3 \pm 1.7$ & $0.3 \pm 2.4$ & & $* * *$ \\
\hline Body mass index $\left(\mathrm{kg} / \mathrm{m}^{2}\right)$ & $-1.1 \pm 0.5$ & $-0.3 \pm 0.2 \quad b$ & $0.3 \pm 0.2^{\mathrm{c}}$ & $1.1 \pm 0.6$ & $0.1 \pm 0.8$ & & $* * *$ \\
\hline Systolic blood pressure (mmHg) & $-2.1 \pm 11.9^{a}$ & $2.0 \pm 9.8 \quad$ ab & $0.6 \pm 11.9^{\text {ab }}$ & $4.5 \pm 12.4$ & $1.3 \pm 11.7$ & & $*$ \\
\hline Diastolic blood pressure $(\mathrm{mmHg})$ & $-2.1 \pm 10.5^{a}$ & $-0.2 \pm 10.1 \mathrm{ab}$ & $0.7 \pm 10.2$ ab & $3.6 \pm 9.7$ & $0.6 \pm 10.2$ & & $*$ \\
\hline Total cholesterol $(\mathrm{mg} / \mathrm{dl})$ & $-8.0 \pm 24.8$ & $3.6 \pm 19.2 \mathrm{~b}$ & $7.8 \pm 22.4^{b}$ & $4.3 \pm 21.0$ & $3.3 \pm 22.5$ & $\dagger^{*}$ & $* * *$ \\
\hline HDL cholesterol (mg/dl) & $2.4 \pm 5.7 \quad$ a & $0.0 \pm 7.3$ & $-0.7 \pm 7.0 \quad$ a & $-4.5 \pm 7.6$ & $-0.9 \pm 7.3$ & & $* * *$ \\
\hline Total cholesterol/HDL cholesterol & $-0.08 \pm 0.68{ }^{a}$ & $0.20 \pm 0.79$ ab & $0.29 \pm 0.79$ ab & $0.56 \pm 1.11$ & $0.27 \pm 0.88$ & $\dagger * * *$ & $* * *$ \\
\hline Triglyceride $(\mathrm{mg} / \mathrm{dl})$ & $-32.9 \pm 82.5^{a}$ & $-13.0 \pm 93.5 \mathrm{ab}$ & $13.5 \pm 90.8$ ab & $23.6 \pm 124.7$ & $1.8 \pm 100.4$ & & $* *$ \\
\hline Uric acid (mg/dl) & $-0.20 \pm 0.76^{a}$ & $0.03 \pm 0.69$ ab & $0.17 \pm 0.74 \mathrm{~b}$ & $0.09 \pm 0.74$ & $0.06 \pm 0.74$ & & $*$ \\
\hline Hemoglobin $\mathrm{A}_{1 \mathrm{c}}(\%)$ & $-0.07 \pm 0.29$ a & $0.10 \pm 0.36$ ab & $0.07 \pm 0.41$ ab & $0.18 \pm 0.56$ & $0.08 \pm 0.43$ & $\dagger * *$ & $*$ \\
\hline Alcohol intake (g/day of ethanol) & $-1.5 \pm 12.8$ & $-0.9 \pm 10.5$ & $0.9 \pm 10.0$ & $1.9 \pm 11.8$ & $0.3 \pm 11.1$ & & \\
\hline Smoking (cigarettes/day) & $0.2 \pm 8.9$ & $0.2 \pm 7.7$ & $0.3 \pm 7.6$ & $-1.4 \pm 7.8$ & $-0.1 \pm 7.9$ & & \\
\hline
\end{tabular}

Results are presented as means \pm standard deviations. $* \mathrm{P}<0.05, * * \mathrm{P}<0.01, * * * \mathrm{P}<0.001$. $\dagger$ Significance by paired $\mathrm{t}$-test. Means with different supercript letters of $\mathrm{a}, \mathrm{b}, \mathrm{c}$ and $\mathrm{d}$ are significantly different among groups according to the change of body weight ( $\mathrm{p}<0.05$ by Scheffé's multiple range test). 
change during one year, statistically significant variances were observed in the changes of systolic and diastolic blood pressures, total cholesterol, HDL cholesterol, the ratio of total cholesterol to HDL cholesterol, triglyceride, uric acid, and $\mathrm{HbA}_{1 \mathrm{c}}$. Concomitant with the decrease of body weight, the levels of systolic and diastolic blood pressures, total cholesterol, triglyceride, uric acid and $\mathrm{HbA}_{1 \mathrm{c}}$ and the ratio of total cholesterol to HDL cholesterol decreased significantly, whereas the HDL cholesterol level increased significantly. On the other hand, there were no significant differences in the changes of alcohol consumption and the number of cigarettes smoked per day among the four subgroups.

To consider the effect of possible confounding factors on the increase of risk-factor levels, a multivariate regression analysis was performed including initial risk-factor level, age, initial body weight, change of body weight, initial alcohol intake, change of alcohol intake, initial cigarette smoking, and change of cigarette smoking as independent variables (Table 3). In addition to the initial risk-factor level, body weight change was an important factor determining the changes of risk factors. The initial alcohol intake and cigarette smoking were significantly positively associated with the change in triglyceride level. Changes in alcohol consumption showed significantly positive associations with the changes in systolic blood pressure and HDL cholesterol. Furthermore, changes in the number of cigarettes smoked per day were significantly related to the changes in triglyceride level and the ratio of total cholesterol to HDL cholesterol.

\section{Discussion}

In this study, two fifths of overweight subjects who participated in the 1-year education program showed the reduction of body weight, but mean values of body weight or BMI did not change significantly. As for the atherogenic risk factors, the levels of total cholesterol, the ratio of total cholesterol to HDL cholesterol and $\mathrm{HbA}_{1 \mathrm{c}}$ showed small but significant increases. There are several ways to interpret the lack of an overall effect in the study. In this population, health examinations are performed twice a year, and health education and counseling are conducted by physicians and practice nurses as required. Thus, the efforts of this program to enhance weight control activity may have been hampered by a ceiling effect in that the level of awareness of this issue had already saturated this population prior to the onset of the program.

The second possibility is that the messages about obesity occurred in the context of recommendations about other behaviors, not all of which were completely compatible. Recent evidence from clinical trials involving weight combined with either smoking cessation ${ }^{28)}$ or sodium restriction ${ }^{29)}$ suggests that the strength of individual treatment effects are sometimes lower when there are multiple treatment objects. For example, emphasis on smoking cessation might adversely affect weight control efforts. Thus, it is conceivable that a workplace program that focused only on obesity might produce greater success. Further investigations are needed to identify the effective approaches to intervention for obesity that focuses on the workplace.

As expected, concomitant with the decrease of body weight, the levels of systolic and diastolic blood pressures, total cholesterol, triglyceride, uric acid and $\mathrm{HbA}_{1 \mathrm{c}}$ and the ratio of total cholesterol to HDL cholesterol decreased, whereas the HDL cholesterol level increased. These results demonstrate that a reduction of body weight is important for controlling atherogenic risk factors in overweight subjects. Obesity has been found to be accompanied by an increased

Table 3. Multivariate regression analysis with the change of the respective factor as a dependent variable and the initial level of the factor, age, initial body weight, alcohol intake and cigarette smoking, and changes of body weight, alcohol intake and cigarette smoking as independent variables

\begin{tabular}{|c|c|c|c|c|c|c|c|c|c|}
\hline \multirow[b]{2}{*}{ Change of variable (Unit) } & \multirow{2}{*}{$\begin{array}{l}\text { Initial level } \\
\text { of variable }\end{array}$} & \multirow{2}{*}{$\begin{array}{c}\text { Age } \\
\text { (years) }\end{array}$} & \multicolumn{2}{|c|}{ Body weight (kg) } & \multicolumn{2}{|c|}{$\begin{array}{c}\text { Alcohol intake } \\
\text { (10 g/day of ethanol) }\end{array}$} & \multicolumn{2}{|c|}{$\begin{array}{c}\text { Smoking } \\
(10 \text { cigarettes/day })\end{array}$} & \multirow{2}{*}{$\begin{array}{c}\text { Cumulative } \\
\mathrm{R}^{2}(\%)\end{array}$} \\
\hline & & & Initial & Change & Initial & Change & Initial & Change & \\
\hline Systolic blood pressure (mmHg) & $-0.30 \pm 0.04 * * *$ & $0.12 \pm 0.09$ & $0.02 \pm 0.08$ & $0.77 \pm 0.26^{* *}$ & $-0.11 \pm 0.33$ & $1.38 \pm 0.59 *$ & $-0.20 \pm 0.39$ & $0.28 \pm 0.82$ & 18.3 \\
\hline Diastolic blood pressure (mmHg) & $-0.42 \pm 0.05^{* * *}$ & $0.10 \pm 0.07$ & $0.05 \pm 0.07$ & $0.69 \pm 0.22 * *$ & $-0.24 \pm 0.27$ & $-0.03 \pm 0.49$ & $0.16 \pm 0.32$ & $1.14 \pm 0.68$ & 27.1 \\
\hline Total cholesterol (mg/dl) & $-0.30 \pm 0.04^{* * *}$ & $0.19 \pm 0.16$ & $0.12 \pm 0.16$ & $1.97 \pm 0.50 * * *$ & $0.62 \pm 0.62$ & $0.24 \pm 1.11$ & $0.19 \pm 0.75$ & $1.22 \pm 1.56$ & 20.3 \\
\hline HDL cholesterol (mg/dl) & $-0.18 \pm 0.04^{* * *}$ & $-0.02 \pm 0.05$ & $-0.04 \pm 0.05$ & $-0.84 \pm 0.17^{* * *}$ & $0.14 \pm 0.21$ & $0.91 \pm 0.38 *$ & $-0.32 \pm 0.25$ & $-0.59 \pm 0.52$ & 16.1 \\
\hline Total cholesterol/HDL cholesterol & $-0.10 \pm 0.05$ & $0.00 \pm 0.01$ & $0.00 \pm 0.01$ & $0.09 \pm 0.02 * * *$ & $0.02 \pm 0.03$ & $-0.04 \pm 0.05$ & $0.03 \pm 0.03$ & $0.15 \pm 0.07 *$ & 9.1 \\
\hline Triglyceride (mg/dl) & $-0.31 \pm 0.06^{* * *}$ & $-0.34 \pm 0.72$ & $-0.07 \pm 0.71$ & $7.64 \pm 2.27 * * *$ & $7.41 \pm 2.86^{*}$ & $8.28 \pm 5.03$ & $10.09 \pm 3.39 * *$ & * $17.32 \pm 7.05^{*}$ & 18.6 \\
\hline Uric acid (mg/dl) & $-0.14 \pm 0.03^{* * * *}$ & $-0.01 \pm 0.01$ & $-0.01 \pm 0.01$ & $0.03 \pm 0.02$ & $0.01 \pm 0.02$ & $0.05 \pm 0.04$ & $0.01 \pm 0.03$ & $-0.02 \pm 0.05$ & 11.1 \\
\hline Hemoglobin $\mathrm{A}_{\mathrm{lc}}(\%)$ & $-0.19 \pm 0.04^{* * *}$ & $0.00 \pm 0.00$ & $0.00 \pm 0.00$ & $0.03 \pm 0.01 * * *$ & $0.00 \pm 0.01$ & $0.01 \pm 0.02$ & $-0.01 \pm 0.01$ & $-0.02 \pm 0.03$ & 13.8 \\
\hline
\end{tabular}

Results are presented as regression coefficients \pm standard error. $* \mathrm{P}<0.05, * * \mathrm{P}<0.01, * * * \mathrm{P}<0.001$. 
risk of $\mathrm{CHD}^{11)}$, but whether obesity is an independent risk factor for CHD is still uncertain, since obesity is highly associated with several established risk factors for CHD such as hypertension $^{1,2)}$, dyslipidemia ${ }^{3-6)}$, hyperuricemia ${ }^{7,8)}$ and glucose intolerance and diabetes mellitus ${ }^{9}{ }^{10)}$. However, the fact that weight reduction in obese patients affects these atherogenic risk factors for CHD makes obesity important for the prevention of $\mathrm{CHD}^{11-16)}$. Furthermore, data from epidemiologic investigations have provided useful insights from repeated weight determinations in population samples, assessment of pattern of obesity, and evaluation of corresponding changes in cardiovascular factors and overall cardiovascular mortality ${ }^{12,16,20-22)}$. Since $21.3 \%$ of middleaged male office workers in this population were deemed overweight (BMI $\geq 25.5 \mathrm{~kg} / \mathrm{m}^{2}$ ), obesity should be a major target for CHD prevention at workplace.

As for alcohol intake, changes in alcohol consumption were significantly positively associated with the changes in systolic blood pressure and HDL cholesterol levels. These findings are consistent with the results of previous studies ${ }^{23-26}$. It can therefore be suggested that an increase in alcohol intake has an anti-atherogenic effect by altering HDL cholesterol, resulting in the decreased risk in serum lipid atherogenicity. However, clinical opinion holds that abstinence from alcohol is fundamental to the control of hypertension.

As for cigarette smoking, many studies have noted an inverse relationship between cigarette smoking and HDL cholesterol levels ${ }^{27-29}$. The triglyceride level in whole serum and a very low density lipoprotein (VLDL) fraction have been also found to increase with cigarette smoking ${ }^{28)}$. Phillips et al. $^{28)}$ have reported a positive association between the amount of cigarettes smoked and beta lipoproteins and posited that this effect is secondary to the higher VLDL triglyceride levels in smokers. We also showed that changes in cigarette smoking were significantly positively associated with the changes in triglyceride levels and the ratio of total cholesterol to HDL cholesterol. Nearly half of the population surveyed for this study smoked cigarettes. Smoking cessation is one of the most effective factors in health education programs at the workplace to reduce the risk of CHD.

During the 1-year program, the modification of most risk factors was accompanied by the reduction of body weight, but the initial risk-factor level was the strongest for the change in risk factor. Because we did not have a control group, we cannot exclude an influence due to regression to the mean in the absence of intervention. However, because laboratory measurements were fairly reliable and baseline data did not differ significantly among the four groups in relation to weight change, we do not expect that this influence may have significantly altered the reported changes. In addition, to consider the effect of interactions of independent variables used in the multivariate regression analysis on the increase of risk-factor levels, the interactions were tested by introducing product terms to models with the original variables, but no significant interactions of independent factors were observed in the multivariate regression models.

Despite these limitations, our findings support the conclusion that although weight control is difficult to achieve, weight reduction modifies the atherogenic risk-factor profile in obese men. More need to be learned about how education programs combine to affect behavior in populations. Additional research is needed to evaluate the extent to which different approaches to intervention that focuses on the environment rather than the person would be more effective in preventing or reversing population-wide obesity.

\section{Acknowledgments}

We would like to express our appreciation to all the employees and the Medical Office of the Osaka Main Office of Takenaka Corporation for their valuable cooperation for this study. We are also grateful to Ryuichi Kaneko and his colleagues at the Japan Labor and Welfare Association for their accurate collecting and coding of the data.

\section{References}

1) Berchtold P, Jorgens V, Finke C, Berger M (1981) Epidemiology of obesity and hypertension. Int J Obesity 5 (suppl 1), 1-7.

2) Blair D, Habicht JP, Sims EA, Sylwester D, Abraham S (1984) Evidence for an increased risk for hypertension with centrally located body fat and the effect of race and sex on this risk. Am J Epidemiol 119, 526-40.

3) Grundy SM, Mok HY, Zech L, Steinberg D, Berman M (1979) Transport of very low density lipoprotein triglycerides in varying degrees of obesity and hypertriglyceridemia. J Clin Invest 63, 1274-83.

4) Gordon T, Fisher M, Ernst N, Rifkind BM (1982) Relation of diet to LDL cholesterol, VLDL cholesterol, and plasma total cholesterol and triglycerides in white adults: The lipid research clinics prevalence study. Arteriosclerosis 2, 502-12.

5) Yano K, Reed DM, Curb JD, Hankin JH, Albers JJ (1986) Biological and dietary correlates of plasma lipids and lipoproteins among elderly Japanese men in Hawaii. Arteriosclerosis 6, 422-33.

6) Denke MA, Sempos CT, Grundy SM (1993) Excess 
body weight. An underrecognized contributor to high blood cholesterol levels in white American men. Arch Intern Med 153, 1093-103.

7) Yano K, Rhoads GG, Kagan A (1977) Epidemiology of serum uric acid among 8000 Japanese-American men in Hawaii. J Chronic Dis 30, 171-84.

8) Goldbourt U, Medalie JH, Herman JB, Neufeld HN (1980) Serum uric acid: correlation with biochemical, anthropometric, clinical and behavioral parameters in 10,000 Israeli men. J Chronic Dis 33, 435-43.

9) Hartz AJ, Rupley DC Jr, Kalkhoff RD, Rimm AA (1983) Relationship of obesity to diabetes: influence of obesity level and body fat distribution. Prev Med 12, 351-7.

10) Stern MP, Haffner SM (1986) Body fat distribution and hyperinsulinemia as risk factors for diabetes and cardiovascular disease. Arteriosclerosis 6, 123-30.

11) Hubert HB, Feinleib M, McNamara PM, Castelli WP (1983) Obesity as an independent risk factor for cardiovascular disease: a 26-year follow-up of participants in the Framingham heart study. Circulation 67, 968-77.

12) Ashley FW Jr, Kannel WB (1974) Relation of weight change to changes in atherogenic traits: the Framingham study. J Chronic Dis 27, 103-14.

13) Caggiula AW, Christakis G, Farrand M, Hulley SB, Johnson R, Lasser NL, Stamler J, Widdowson G (1981) The multiple risk factor intervention trial (MRFIT). IV. Intervention on blood lipids. Prev Med 10, 443-75.

14) Hughes TA, Gwymme JT, Switzer BR, Herbst C, White $\mathrm{G}$ (1984) Effects of caloric restriction and weight loss on glycemic control, insulin release and resistance, and atherosclerotic risk in obese patients with type II diabetes mellitus. Am J Med 77, 7-17.

15) Wood PD, Stefanick ML, Dreon DM, Frey-Hewitt B, Garay SC, Williams PT, Superko HR, Fortmann SP, Albers JJ, Vranizan KM, Ellsworth NM, Terry RB, Haskell WL (1988) Changes in plasma lipids and lipoproteins in overweight men during weight loss through dieting as compared with exercise. N Engl J Med 319, 1173-9.

16) Lissner L, Odell PM, D'Agostino RB, Stokes J III, Kreger BE, Belanger AJ, Brownell KD (1991) Variability in body weight and health outcomes in the Framingham population. N Engl J Med 324, 1839-44.

17) Minowa S (1962) Study on standard weights for Japanese adults: charts of Minowa's relative weight index. Jpn J Med 1988, 24-8 (in Japanese).

18) Hall SM, Tunstall CD, Vila KL, Duffy J (1992) Weight gain prevention and smoking cessation: cautionary findings. Am J Public Health 82, 799-803.

19) Hypertension prevention trial Research Group (1990) The hypertension prevention trial: three-year effects of dietary changes on blood pressure. Arch Intern Med 150, 153-62.

20) Garrison RJ, Kannel WB, Stokes J III, Castelli WP (1987) Incidence and precursors of hypertension in young adults: the Framingham offspring study. Prev Med 16, 235-51.

21) Wilson PWF, McGee DL, Kannel WB (1981) Obesity, very low density lipoproteins and glucose intolerance over fourteen years. Am J Epidemiol 114, 697-704.

22) Kannel WB, Cupples LA, Ramaswami R, Stokes J III, Kreger BE, Higgins M (1991) Regional obesity and risk of cardiovascular disease: the Framingham study. J Clin Epidemiol 44, 183-90.

23) Castelli WP, Doyle JT, Gordon T, Hames CG, Hjortland MC, Hulley SB, Kagan A, Zukel WJ (1977) Alcohol and blood lipids. The cooperative lipoprotein phenotyping study. Lancet ii, 153-5.

24) Ernst N, Fisher M, Smith W, Gordon T, Rifkind BM, Little JA, Mishkel MA, Williams OD (1980) The association of plasma high-density lipoprotein cholesterol with dietary intake and alcohol consumption. The lipid research clinics prevalence study. Circulation 62 (suppl IV), 41-52.

25) Frimpong NA, Lapp JA (1989) Effects of moderate alcohol intake in fixed or variable amounts on concentration of serum lipids and liver enzymes in healthy young men. Am J Clin Nutr 50, 987-91.

26) Ueshima H, Mikawa K, Baba S, Sasaki S, Ozawa H, Tsushima M, Kawaguchi A, Omae T, Katayama Y, Kayamori Y, Ito K (1993) Effect of reduced alcohol consumption on blood pressure in untreated hypertensive men. Hypertension 21, 248-52.

27) Criqui MH, Wallace RB, Heiss G, Mishkel M, Schonfeld G, Jones GT (1980) Cigarette smoking and plasma high-density lipoprotein cholesterol. The lipid research clinics program prevalence study. Circulation 62 (suppl IV), 70-6.

28) Phillips NR, Havel RJ, Kane JP (1981) Levels and interrelationships of serum and lipoprotein cholesterol and triglycerides. Association with adiposity and the consumption of ethanol, tobacco, and beverages containing caffeine. Arteriosclerosis 1, 13-24.

29) Hegarty KM, Turgiss LE, Mulligan JJ, Cluette JE, Kew RR, Stack DJ, Hojnacki JL (1982) Effects of cigarette smoking on high density lipoprotein phospholipids. Biochem Biophys Res Commun 104, 212-9. 